\title{
The synthesis, chemical and biological properties of dichlorido(azpy)gold(III) chloride (azpy = 2-(phenylazo)pyridine) and the gold-induced conversion of the azpy ligand to the chloride of the novel tricyclic pyrido[2,1-c][1,2,4]benzotriazin-11-ium cation
}

\author{
Ariadna Garza-Ortiz ${ }^{\text {a }}$, Hans den Dulk ${ }^{\text {a }}$, Jaap Brouwer a, Huub Kooijman ${ }^{\text {b }}$, \\ Anthony L. Spek ${ }^{\text {, }}$, Jan Reedijk ${ }^{\text {a,* }}$ \\ ${ }^{a}$ Leiden Institute of Chemistry, Gorlaeus Laboratories, Leiden University, P.O. Box 9502, 2300 RA Leiden, The Netherlands \\ ${ }^{\mathrm{b}}$ Bijvoet Center for Biomolecular Research, Crystal and Structural Chemistry, Utrecht University, Padualaan 8, 3584 CH, Utrecht, The Netherlands
}

Received 22 March 2007; received in revised form 9 May 2007; accepted 9 May 2007

Available online 2 June 2007

Dedicated to the memory of Ed Stiefel

\begin{abstract}
A new $\mathrm{Au}(\mathrm{III})$ coordination compound with the ligand 2-(phenylazo)pyridine has been synthesized and fully characterized by means of elemental analysis, IR, UV-visible, conductivity measurements, NMR, electrospray ionization (ESI-MS) and inductively coupled plasma optical emission spectrometry (ICP-OES). The chemical stability of the cation in this compound, $\left.[\mathrm{Au}(\mathrm{azpy}) \mathrm{Cl}]_{2}\right]^{+}(\mathrm{abbreviated}$ : $A u-a z p y)$, was analyzed by means of several physicochemical methods. While stable in the solid state, stability studies performed with the gold compound in solution showed an unexpected and unprecedented reactivity. A cationic organic derivative of 2-(phenylazo)pyridine, (abbreviated: pyrium), was produced from the solution and has been isolated as its chloride salt and characterized by crystal structure determination, elemental analysis, NMR, ESI-MS and conductivity studies in solution. This cyclization reaction is reported for the first time in the case of gold coordination compounds.

The Au adduct and the pyrium cation were investigated as potential cytotoxic and anticancer agents, and both show moderate to high cytotoxic properties in cisplatin-sensitive and cisplatin-resistant ovarian carcinoma cell lines, A2780; and cisplatin-sensitive and cisplatinresistant murine lymphocytic leukemia cell lines, L1210. Significant anticancer activity against the cisplatin resistant cell lines was found for the pyrium salt, ruling out the occurrence of cross resistance phenomena.
\end{abstract}

(c) 2007 Elsevier Inc. All rights reserved.

Keywords: Gold(III) complexes; 2-(phenylazo)pyridine; Cytotoxic activity; Cyclization; Charged aromatic rings; $N$-Heterocyclic cation; Cyclodehydrogenation

\section{Introduction}

A major aim of research in the field of antitumor-active metal complexes is to develop new drugs for the treatment of cancer. The continuous success of cisplatin in the clinic is striking and undeniable. It belongs to the most widely

\footnotetext{
${ }^{*}$ Corresponding author. Tel.: +31 71527 4459; fax: +31 715274671.

E-mail address: reedijk@chem.leidenuniv.nl (J. Reedijk).
}

used anticancer drugs, employed in the treatment of around $70 \%$ of all cancer patients [1]. Despite of the advantages of cisplatin in comparison to other anticancer drugs, a high general toxicity (nephro-, neuro- and ototoxicity) leading to undesirable side-effects $[2,3]$ has been reported. Also resistance of tumor cells to cisplatin treatment (either developed or intrinsic) has been reported in addition to its limited applicability to a relatively small range of cancer types [4]. 
To overcome such disadvantages new platinum-based drugs have been prepared and evaluated for many years $[5,6]$. The search for an agent with increased anticancer activity still remains an elusive goal; that is why different metal-coordinated compounds have also been studied. Metal-based compounds with titanium, rhodium, rhenium, ruthenium, gallium, gold, tin, cobalt and copper have been synthesized and many of them have shown promising in vitro anticancer results [7].

Gold's application to treat a variety of ailments [8-10] dates back to ancient times in the Arabic and Chinese civilizations [11]. At the end of 19th century, Koch discovered the bacteriostatic properties of gold cyanide, $\mathrm{K}\left[\mathrm{Au}(\mathrm{CN})_{2}\right]$, towards tubercle bacillus. Further studies demonstrated the reduction of inflammation, effect that was rigorously studied in the field of rheumatoid arthritis and this in fact is considered the first analytical application of gold compounds properties in therapeutics. The compounds used in the treatment of rheumatoid diseases [12] are currently the major clinical use for gold compounds, an example being Auranofin. Undoubtedly, important advances in the chemical reactivity and pharmacology of gold drugs have emerged and further applications were hypothesized from this knowledge, generating new studies of gold compounds for the treatment of cancer, HIV and malaria $[8,10,13]$.

The design and testing of gold complexes for antitumor activity was stimulated by four key observations, i.e.: (1) Analogies in ligand-exchange behavior between square planar complexes of $\mathrm{Pt}(\mathrm{II})$ and $\mathrm{Au}(\mathrm{III})$, and also their similar isoelectronic- and isostructural behavior; (2) analogy to the immunomodulatory effects of gold(I) antiarthritic agents; (3) coordination of gold(I) and gold(III) with known antitumor agents to form a new compounds with enhanced activity and (4) some gold(III) complexes present a good enough stability in aqueous and physiological environments. This stability in water may be modulated by the appropriate choice of ligands.

The molecule 2-(phenylazo)pyridine (azpy) is an azopyridine ligand system which has the $\mathrm{N}=\mathrm{CN}=\mathrm{N}$ chromophore $[14,15]$. This asymmetric bidentate ligand coordinates via the pyridine and aza nitrogen atoms, forming a stable 5 -membered chelating ring $[16,17]$ which is known to be capable of acting as both $\sigma$ donor and $\pi$ acceptor.

Many gold(III) compounds are able to overcome to a large extent resistance to cisplatin, suggesting a different mechanism of action with respect to cisplatin [18-21]. Mechanistic studies indeed did suggest that, in contrast to cisplatin, DNA is not the primary target of gold complexes. Rather, the cytotoxicity is mediated by their ability to slow down mitochondrial function $[22,23]$ and to inhibit protein synthesis.

In a search to better understand the chemical and physical behavior of biologically relevant gold complexes, the complex $\left[\mathrm{Au}(\right.$ azpy $\left.) \mathrm{Cl}_{2}\right] \mathrm{Cl} \cdot 2 \mathrm{H}_{2} \mathrm{O}($ Au-azpy) has been prepared and fully characterized and its cytotoxicity has been tested in vitro in a number of tumor cell lines. In addition, it is demonstrated that the ligand azpy is susceptible of remarkable and unprecedented metal-mediated chemical reactions. The phenyl moiety shows a cyclization onto the pyridine ring, generating a completely new $N$-heterocyclic cation (abbreviated: pyrium) with high cytotoxic activity particularly remarkable in cisplatin-resistant cell lines.

\section{Experimental}

\subsection{Materials and methods}

Chemicals and solvents (analytical reagent grade) were purchased from Acros, Nova-Biochem and Biosolve and used without further purification treatments unless otherwise stated. The 2-aminopyridine and nitrosobenzene were purchased from Fluka and Sigma-Aldrich, respectively. Sodium hydroxide and $\mathrm{HAuCl}_{4} \cdot 3 \mathrm{H}_{2} \mathrm{O}$ were purchased from Merck. All other reagents were of high purity and used as purchased without any further purification.

\subsection{Instrumental techniques}

Different techniques were employed in the characterization of the ligand, coordination compounds and tricyclic derivative synthesized. Elemental analyses were performed with a Perkin Elmer series II CHNS/O 2400 analyzer. Gold concentration was determined with a VISTA-MPX charged-coupled simultaneous ICP-OES spectrometer (inductively coupled plasma optical emission spectrometer), which was measured in $\mathrm{mg} / \mathrm{L}$ at 242.794 and $267.594 \mathrm{~nm}$. The experiments were carried out in duplicate. Electrospray mass spectra were recorded on a Finnigan TSQ-quantum instrument using an electrospray ionization technique (ESI-MS). The eluent used was the mixture acetonitrile:water 80:20. The UV-visible (UV-vis) spectra were recorded using a Varian CARY $50 \mathrm{UV} /$ vis spectrophotometer. NMR experiments were carried out with a Bruker 300 DPX spectrometer. All spectra were recorded at $21^{\circ} \mathrm{C}$, unless otherwise indicated. Temperature was kept constant using a variable temperature unit. The software XWIN-NMR and XWIN-PLOT were used for edition of the NMR spectra. Tetramethylsilane (TMS) or the deuterated solvent residual peaks were used for calibration. In addition $2 \mathrm{D}{ }^{1} \mathrm{H}$ COSY spectra were recorded to confirm the proton assignments. The IR spectra obtained for the products mentioned in this work in the $4000-300 \mathrm{~cm}^{-1}$ range were recorded as solid with a Perkin Elmer FT-IR Paragon 1000 spectrophotometer with a single-reflection diamond ATR P/N 10500. Conductivity measurements were carried out with a Philips PW9526 digital conductivity meter for freshly prepared $1 \mathrm{mM}$ solutions in nitromethane (AR grade) at $25^{\circ} \mathrm{C}$. The measuring cell consists of two parallel platinum electrodes at a distance of $1 \mathrm{~cm}$.

Full X-ray crystal structure determination studies were performed for the crystals obtained from pyrium. The 
corresponding information and procedures applied are described in the supplementary data.

\subsection{Preparations of the compounds}

2-(Phenylazo)pyridine (azpy): The ligand was prepared as described in the literature [14] with minor modifications in the purification procedure.

Dichlorido $\{2$-(phenylazo)pyridine $\}$ gold(III) chloride dihydrate, $\left[\mathrm{Au}\left(\right.\right.$ azpy) $\left.\mathrm{Cl}_{2}\right] \mathrm{Cl} \cdot 2 \mathrm{H}_{2} \mathrm{O}$ (abbreviated: $A u$-azpy): The compound was synthesized according to the following procedure: $0.05 \mathrm{~g}(0.127 \mathrm{mmol})$ of $\mathrm{HAuCl}_{4} \cdot 3 \mathrm{H}_{2} \mathrm{O}$ was added to a solution of $0.00070 \mathrm{~g}(0.0165 \mathrm{mmol})$ of $\mathrm{LiCl}$ in $2.5 \mathrm{~mL}$ of dichloromethane and one drop of methanol. A solution of the corresponding ligand, 2-(phenylazo)pyridine $(0.025 \mathrm{~g}, 0.136 \mathrm{mmol})$, in $2.5 \mathrm{~mL}$ of dichloromethane was added to the gold solution. The system was kept under reflux for $1 \mathrm{~h}$. The solid formed after this time was collected by filtration, washed plenty with dichloromethane and cold water and dried with hexane and diethyl ether. Yield: $58.78 \%$ (0.07465 mmol, $0.03901 \mathrm{~g})$. Elemental analysis for $\mathrm{AuC}_{11} \mathrm{H}_{13} \mathrm{~N}_{3} \mathrm{Cl}_{3} \mathrm{O}_{2}$ : Calculated (\%): C, 25.28; N, 8.04; H, 2.51 and $\mathrm{Au}, 37.69$. Found (\%): C, 25.23; N, 8.15; H, 2.09 and $\mathrm{Au}$, 36.7. ESI-MS: $m / z=472.30,\{2[\mathrm{Au}(\mathrm{az}-$ py) $\left.\left.\mathrm{Cl}_{2}\right]\left(\mathrm{CH}_{3} \mathrm{CN}\right)\right\}^{2+}$. IR: $1616-1592,1526-1486,1472$, $781,678,537-522$ and $352 \mathrm{~cm}^{-1}$.UV-vis in acetonitrile $\left(\lambda_{\max }\left(\log \varepsilon_{\mathrm{M}}\right)\right): 225(4.782), 335(4.386)$ and $440(2.87) .{ }^{1} \mathrm{H}$ NMR $\left(300 \mathrm{MHz}\right.$, acetone, $2{ }^{\circ} \mathrm{C}, \mathrm{s}=$ singlet, $\mathrm{d}=$ doublet, $\mathrm{t}=$ triplet and $\mathrm{m}=$ multiplet $): \delta=9.24620\left(\mathrm{~d}, 1 \mathrm{H}, \mathrm{H}_{6}\right)$, $9.02453\left(\mathrm{t}, 1 \mathrm{H}, \mathrm{H}_{4}\right), 8.66925\left(\mathrm{~d}, 1 \mathrm{H}, \mathrm{H}_{3}\right), 8.38438(\mathrm{t}, 1 \mathrm{H}$, $\left.\mathrm{H}_{5}\right), 8.14607\left(\mathrm{~m}, 2 \mathrm{H}, \mathrm{H}_{\mathrm{o}}\right)$ and $7.77802 \mathrm{ppm}\left(\mathrm{m}, 3 \mathrm{H}, 2 \mathrm{H}_{\mathrm{m}}\right.$ and $\left.\mathrm{H}_{\mathrm{p}}\right) . \Lambda_{\mathrm{M}}\left(\mathrm{CH}_{3} \mathrm{NO}_{2}\right)=86 \Omega^{-1} \mathrm{~cm}^{2} \mathrm{~mol}^{-1}$.

Pyrido[2,1-c][1,2,4]benzotriazin-11-ium chloride, $\mathrm{C}_{11} \mathrm{H}_{8} \mathrm{~N}_{3} \mathrm{Cl} \cdot \mathrm{H}_{2} \mathrm{O}$ (abbreviated: pyrium): The title compound was synthesized by the following procedure: $0.03 \mathrm{~g}$ $(0.0574 \mathrm{mmol})$ of $\left[\mathrm{Au}(\right.$ azpy $\left.) \mathrm{Cl}_{2}\right] \mathrm{Cl} \cdot 2 \mathrm{H}_{2} \mathrm{O}$ were solved in $16.57 \mathrm{~mL}$ of acetone. The system was kept under atmospheric conditions at $294 \mathrm{~K}$. Pale yellow needles were obtained after 14 days. The crystals formed after this time were collected by filtration, washed plenty with cold acetone and dried with diethyl ether. Yield: 64.88\% $(0.03721 \mathrm{mmol}, \quad 8.77 \mathrm{mg})$. Elemental analysis for $\mathrm{C}_{11} \mathrm{H}_{10} \mathrm{~N}_{3} \mathrm{ClO}$ : Calculated (\%): $\mathrm{C}, 56.06 ; \mathrm{N}, 17.83$ and $\mathrm{H}$, 4.28. Found (\%): C, 55.52; N, 17.68 and H, 4.18. ESIMS: $m / z=181.94, \mathrm{C}_{11} \mathrm{H}_{8} \mathrm{~N}_{3}^{+}$. ${ }^{1} \mathrm{H}$ NMR $(300 \mathrm{MHz}$, acetone, $21^{\circ} \mathrm{C}, \mathrm{s}=$ singlet, $\mathrm{d}=$ doublet, $\mathrm{t}=$ triplet and $\mathrm{m}=$ multiplet $): \delta=10.6312\left(\mathrm{~d}, 1 \mathrm{H}, \mathrm{H}_{6}\right), 9.5012(\mathrm{~d}, 1 \mathrm{H}$, $\left.\mathrm{H}_{3}^{\prime}\right), 9.3472\left(\mathrm{~m}, 2 \mathrm{H}, \mathrm{H}_{\mathrm{m} 1}\right.$ and $\left.\mathrm{H}_{4}\right), 9.1410\left(\mathrm{~d}, 1 \mathrm{H}, \mathrm{H}_{\mathrm{o}}\right)$, $8.8872\left(\mathrm{t}, 1 \mathrm{H}, \mathrm{H}_{5}\right), 8.6730\left(\mathrm{t}, 1 \mathrm{H}, \mathrm{H}_{\mathrm{p}}\right)$ and $8.5156 \mathrm{ppm}$ (t, $1 \mathrm{H}, \mathrm{H}_{\mathrm{m} 2}$ ).

\subsection{Electronic spectra}

The absorption spectra in the UV-vis region were recorded on a Varian CARY $50 \mathrm{UV} /$ vis spectrophotometer operating at room temperature. The electronic spectra were recorded in freshly prepared acetonitrile solutions due to the poor solubility in water.

\subsection{Stability studies}

Stability studies were developed in case of the compound Au-azpy in solution and followed by ${ }^{1} \mathrm{H}$ NMR. A solution of the compound was prepared by dissolving $1.05 \mathrm{mg}$ in $0.58 \mathrm{~mL}$ of deuterated acetone with TMS used as NMR internal standard. The solution in the NMR tube was closed with a proper cap. The number of scans was kept constant in all the determinations.

Several conditions were tested in order to detect the main factors that could take part in the formation of the tricyclic cation. Factors as light, solvent nature, temperature and atmosphere composition where all considered and analyzed.

The chemical changes in the sample were detected by time-dependent consecutive measurements with ${ }^{1} \mathrm{H}$ NMR. The stability studies were prolonged till no further changes in the spectra were detected. With all the data registered, plots of the chemical shifts against time were used to analyse the decomposition of azpy and formation of pyrium.

\subsection{Cytotoxicity assays and $I C_{50}$ determination}

The human ovarian cell lines, A2780 and A2780R, sensitive and resistant to cisplatin, were derived from untreated patient cells [24]. The cells were grown as monolayers in Dulbecco's modified Eagle's Medium (Gibco, Paisley, Scotland) supplemented with 10\% fetal calf serum (Hyclone, Logan, USA), penicillin (100 units/ml: Dufecha, Netherlands) and streptomycin (100 $\mu \mathrm{g} / \mathrm{ml}$ : Dufecha, Netherlands). The murine lymphocytic leukemia cell lines, L1210 and L1210R, sensitive and resistant to cisplatin, respectively, were cultured in Dulbecco's modified Eagle's Medium supplemented with 10\% fetal calf serum (Hyclone, Logan, USA), penicillin (100 units/ml: Dufecha, Netherlands) and streptomycin $(100 \mu \mathrm{g} / \mathrm{ml}$ : Dufecha, Netherlands). During growth, the cells grew partly in suspension and partly adherent to the flask. The cisplatin-resistant L1210R was obtained by exposure of L1210 cells to cisplatin at the concentration of $10 \mu \mathrm{M}$ over a period of 3 months and subsequent cloning [25]. For the cell growth assay, cells (2000 cells/100 $\mu \mathrm{l}$ of complete medium/well) were pre-cultured in 96 multi-well plates for $48 \mathrm{~h}$ at $37^{\circ} \mathrm{C}$ in a $7 \% \mathrm{CO}_{2}$ containing incubator and subsequently treated with the tested compounds for $72 \mathrm{~h}$. The stock solutions of the compounds in the corresponding solvent were diluted in five subsequent dilutions in order to have final concentrations of $0-200 \mu \mathrm{M}$ by triplicate. Cisplatin was used as a control and was solved in Millipore water as well. After $72 \mathrm{~h}$ incubation time, the surviving cells in cultures treated with the compounds were detected using the MTT method $[26,27]$. MTT is a yellow water-soluble tetrazolium salt. The MTT (3-(4,5-dimethylthiazol 2-yl)-2,5-diphenyltetrazolium bromide) assay is a simple non-radioactive 
colorimetric assay to measure cell cytotoxicity, proliferation or viability. Metabolically active cells are able to convert the dye to a water-insoluble dark blue formazan by reductive cleavage of the tetrazolium ring $[28,29]$. MTT in PBS (100 $\mu 1$ at $2.5 \mathrm{mg} / \mathrm{ml})$ was added and the cells were incubated for $2 \mathrm{~h}$. The solution was carefully removed and the remaining crystals were dissolved in $100 \mu$ of DMSO after which the absorbance at $590 \mathrm{~nm}$ of each well was determined using a BIO-RAD microplate model 550 reader. The growth inhibition was determined relative to untreated controls. Data were used for construction of response curves and determination of the $\mathrm{IC}_{50}$ (concentration of the complex that restricts cell growth to $50 \%$ of that compared with the control) values was graphically done by use of GraphPad Prism software, version 3.02, 2000 .

\section{Results and discussion}

\subsection{Synthesis and characterization}

\subsubsection{Dichlorido $\{2-($ phenylazo $)$ pyridine $\}$ gold(III) chloride dihydrate, $\left[\mathrm{Au}(\right.$ azpy $\left.) \mathrm{Cl}_{2}\right] \mathrm{Cl} \cdot 2 \mathrm{H}_{2} \mathrm{O}, \mathrm{Au}$-azpy}

The synthetic procedure followed is shown in detail in Scheme 1. The ESI-MS spectrum exhibits a positive peak at $m / z=472.30$, which corresponds to the cationic structure, $\left\{2\left[\mathrm{Au}(\text { azpy }) \mathrm{Cl}_{2}\right] \mathrm{CH}_{3} \mathrm{CN}\right\}^{2+}$. A mixture of $\mathrm{CH}_{3} \mathrm{CN} /$ $\mathrm{H}_{2} \mathrm{O}, 80: 20$ was used as eluent. A fragmentation ion was observed at $m / z=183.52$ which corresponds to the free azpy ligand. All MS peaks exhibited the correct isotopomer distribution mainly derived from the number of chlorine atoms. The coordination compound showed a $\Lambda_{\mathrm{M}}$ value recorded in nitromethane at $25^{\circ} \mathrm{C}$ of $86 \Omega^{-1} \mathrm{~cm}^{2} \mathrm{~mol}^{-1}$ which occurs in the range from $65-105 \Omega^{-1} \mathrm{~cm}^{2} \mathrm{~mol}^{-1}$, attributed to 1:1 electrolyte [30].

From IR studies, several changes were observed in the spectrum of Au-azpy when comparing with the spectrum obtained from the free ligand. Table S1 summarizes the most important peaks, the corresponding assignment and frequencies in the mid-IR region, confirming the presence of the ligand and coordinating to gold. The characteristic peak assigned to $\mathrm{Au}-\mathrm{Cl}$ bond was observed in Au-azpy spectrum at $352 \mathrm{~cm}^{-1}$, a value which is in accordance with a chloride ion in a trans position to the nitrogen of the azo group [31].

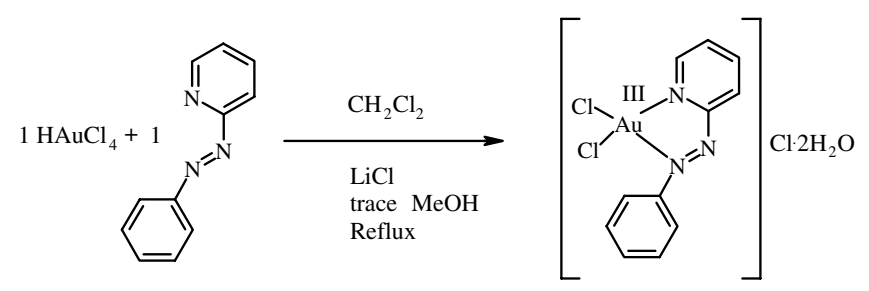

Scheme 1. Synthesis scheme of Au-azpy compound (details are in the experimental part).
${ }^{1} \mathrm{H}$ NMR spectroscopy also shows clear evidence of coordination. Fig. 1 shows free azpy and $A u$-azpy spectra for comparison reasons. From the NMR spectrum of $A u$ $a z p y$, seven different peaks accounting for nine protons are observed; this pattern can be explained by asymmetry in the product formed which is larger than the asymmetry observed in the ligand by itself. The integration values are in agreement with the proposed structure (assignment data, $\delta=9.24620\left(\mathrm{~d}, 1 \mathrm{H}, \mathrm{H}_{6}\right), 9.02453\left(\mathrm{t}, 1 \mathrm{H}, \mathrm{H}_{4}\right), 8.66925$ $\left(\mathrm{d}, 1 \mathrm{H}, \mathrm{H}_{3}\right), 8.38438\left(\mathrm{t}, 1 \mathrm{H}, \mathrm{H}_{5}\right), 8.14607\left(\mathrm{~m}, 2 \mathrm{H}, \mathrm{H}_{\mathrm{o}}\right)$ and $7.77802 \mathrm{ppm}\left(\mathrm{m}, 3 \mathrm{H}, 2 \mathrm{H}_{\mathrm{m}}\right.$ and $\left.\left.\mathrm{H}_{\mathrm{p}}\right)\right)$. The very clean spectrum indicates a high purity of the sample. The integral ratio between the peaks also correlates with the chemical structure proposed.

The $\mathrm{H}_{6}$ doublet in this coordination compound has been assigned on account of its $3 \mathrm{~J}$ coupling (typical values of around $5 \mathrm{~Hz}$ for the $\mathrm{H}_{6}$ versus around $9 \mathrm{~Hz}$ for the $\mathrm{H}_{3}$ doublet, as concluded from selective substitution of the pyridine-ring protons) and assignments of the $\mathrm{H}_{4}$ and $\mathrm{H}_{5}$ were made on the basis of $2 \mathrm{D}{ }^{1} \mathrm{H}$ COSY experiments (Fig. 2). The broadness in the peak $\left(\mathrm{H}_{6}\right)$ is attributed to the presence of the electronegative pyridine nitrogen.

The deshielding effect produced for $\mathrm{H}_{6}$ is the result of the pyridine nitrogen coordination to the metallic electrophilic centre, as well as the deshielding effect of the chlorides. As a result of the aromatic resonance in the pyridine ring the coordination effect could also be the reason for the downfield shift of $\mathrm{H}_{4}$ located at the para position.

As expected, the deshielding effect on the aromatic nonpyridine ring is not so strong, but certainly some differences can be observed by comparing with starting material. The absence of single peaks for the two $\mathrm{H}_{\mathrm{o}}$ and $\mathrm{H}_{\mathrm{m}}$ atoms in the spectrum indicates a reduced symmetry for the phenyl moiety, which could be generated by intramolecular interactions e.g. by a $\mathrm{Cl}-\mathrm{H}_{\mathrm{o}}$ hydrogen bond.

\subsection{Electronic spectra}

The absorption spectra in the UV-vis region were recorded using a Varian CARY $50 \mathrm{UV} /$ vis spectrophotometer operating at room temperature. The electronic spectra were recorded in freshly prepared acetonitrile solutions $(0.0985 \mathrm{mM}$ and $1.04 \mathrm{mM})$ due to the poor solubility in water and the higher stability of $A u$-azpy in acetonitrile.

The spectrum is characterized by intense peaks in the region that comprises $200-550 \mathrm{~nm}$. The bands appearing at $225\left(\log \varepsilon_{\mathrm{M}}=4.782\right)$ and $335\left(\log \varepsilon_{\mathrm{M}}=4.386\right)$ are considered mainly as intraligand charge-transfer transitions, as they have high molar extinct coefficients and could be observed in the free ligand [32] as well (Fig. 3). In the particular case of the absorption peak at $225 \mathrm{~nm}$ a higher LMCT nature is observed due to the extremely high molar extinction coefficient, which is comparable to the one present in the $\left[\mathrm{AuCl}_{4}\right]^{-}$anion $\left(230 \mathrm{~nm}, \log \varepsilon_{\mathrm{M}}=4.5359\right)$. The energy of the $\pi \rightarrow \pi^{*}$ transition in a free azpy (at $315 \mathrm{~nm}$ ) is lower for $A u$-azpy (at $335 \mathrm{~nm}$ ), which is consistent with 


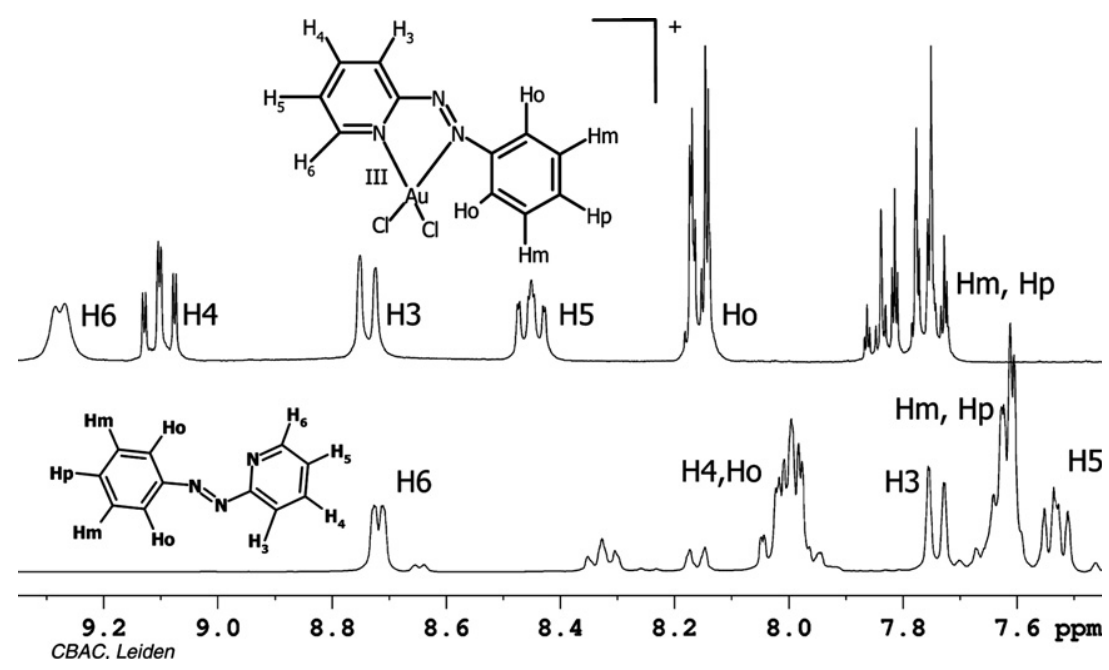

Fig. 1. ${ }^{1} \mathrm{H}$ NMR spectra recorded in deuterated acetone at $21^{\circ} \mathrm{C}$, using TMS as internal standard. Aromatic region. The spectrum of free $a z p y$ in the same solvent is also depicted for comparison.

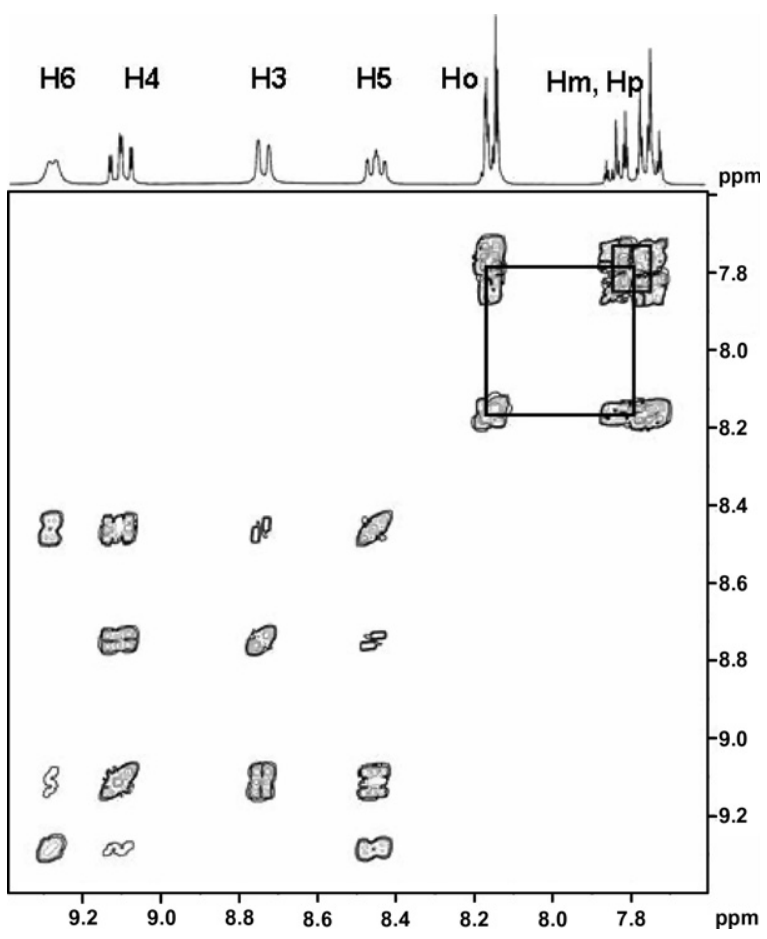

Fig. 2. $2 \mathrm{D}{ }^{1} \mathrm{H}$ COSY spectrum recorded in deuterated acetone at $21^{\circ} \mathrm{C}$, using TMS as internal standard. Aromatic region only.

coordination of azpy. The transitions involved in a $5 \mathrm{~d}^{8}$ system are of forbidden $\mathrm{g}-\mathrm{g}$ nature and explain the molar extinction values below 100. The typical band for the charge-transfer transition $\mathrm{Cl} \rightarrow \mathrm{Au}(\mathrm{III})$ [33] localized in $\mathrm{HAuCl}_{4}$ at $315 \mathrm{~nm}$ cannot be observed due to overlapping with the other bands. It is not possible either to detect any reduction to $\mathrm{Au}(\mathrm{I})$, as there is no absorption at $246 \mathrm{~nm}$ [34]. The molar extinction coefficient for the lowest energy peak is 401 in case of azpy $(450 \mathrm{~nm})$ and 741 in case of $A u$-azpy (440 nm).

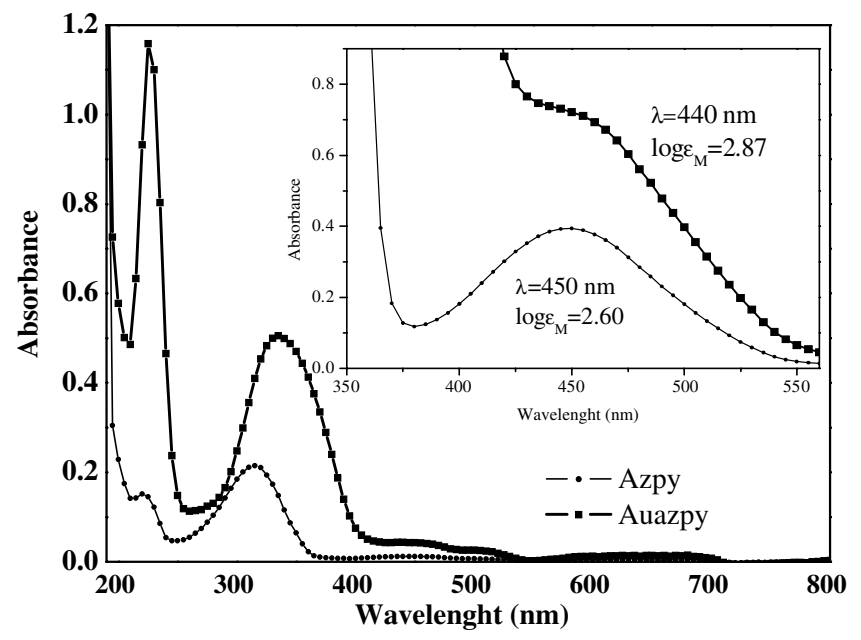

Fig. 3. UV-vis absorption spectra of $a z p y$ and $A u$-azpy in acetonitrile.

\subsection{Stability studies}

Au-azpy shows a high stability in the solid state under atmospheric conditions. Stability studies in solutions were performed and the changes followed by ${ }^{1} \mathrm{H}$ NMR spectroscopy.

Several factors involved in the chemical transformation of Au-azpy were considered, such as the influence of solvent, temperature, the presence of dioxygen and also the influence of light, as light sensitivity of $\mathrm{Au}(\mathrm{III})$ complexes is well known [34].

In Fig. 4, the spectral changes as a function of time in deuterated acetone are presented. Some resonance peaks gradually appeared while some others disappeared, clearly suggesting a reaction taking place. Two important observations need to be mentioned: (1) Intense downfield shifts were observed and (2) the integration values for the final product, approximately after 11 days, evidenced the 

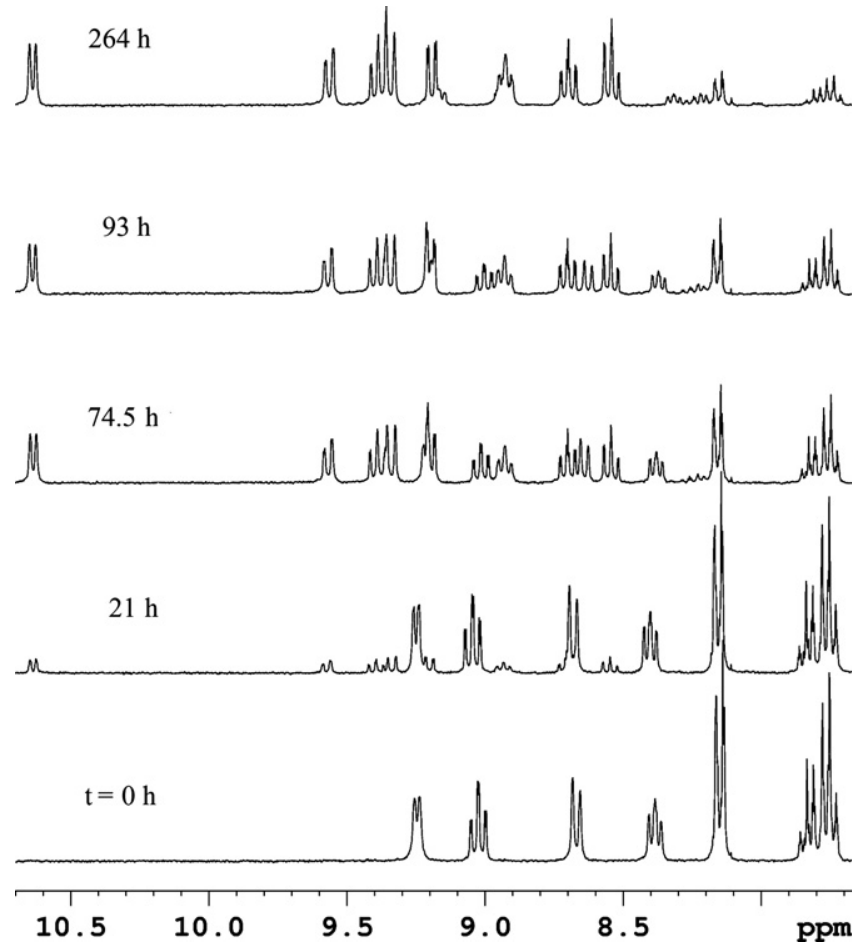

Fig. 4. Time-dependent ${ }^{1} \mathrm{H}$ NMR study of $A u$-azpy in deuterated acetone at $21^{\circ} \mathrm{C}$, using TMS as internal standard. Aromatic region only.

presence of eight protons, instead of the original nine protons. The studies were also performed in acetonitrile and methanol with similar results (spectra not shown). Keeping the sample under an argon atmosphere, on the other hand, prevented these changes to occur. The same conversion results were observed when the sample was kept at $5{ }^{\circ} \mathrm{C}$ in air, but in the dark.

A plot of the integration values as a function of time for some resonance peaks is presented in Fig. 5. Although not

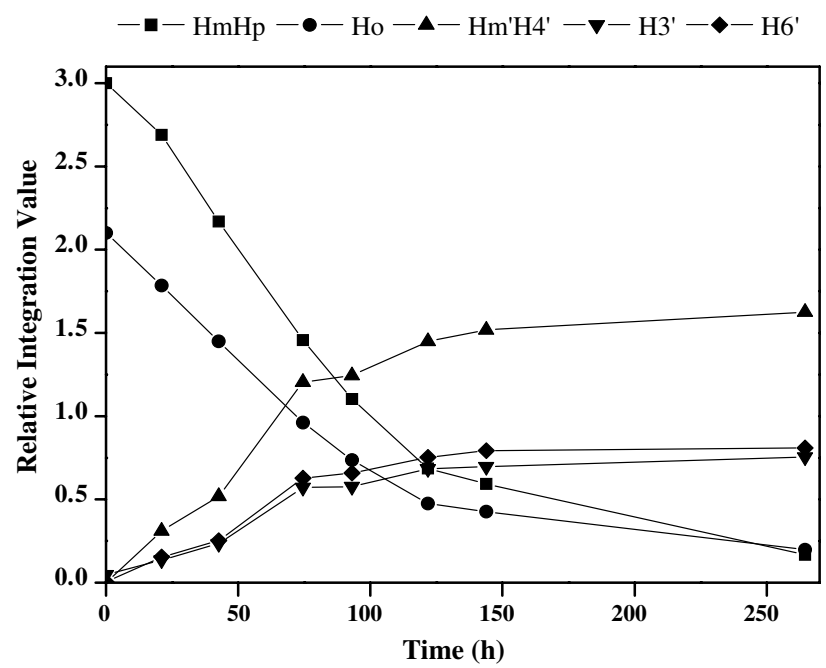

Fig. 5. Proton resonance peak integration values as a function of time in a deuterated acetone solution of $A u$-azpy at $21^{\circ} \mathrm{C}$. Shifts for new peaks: $\mathrm{H}_{6}^{\prime}$, $10.6312 ; \mathrm{H}_{3}^{\prime}, 9.5012$ and $\mathrm{H}_{m}^{\prime} / \mathrm{H}_{4}^{\prime}, 9.3472$. studied in detail, the role of the solvent also must be critical here, in allowing the chemical transformation, as is well known in the chemistry of gold(III) coordination compounds [35].

Several hypothetic structures were considered to explain these changes in the spectra, but more information was needed in order to assure the structure proposal. Anyway it appears sure that azpy prevents the reduction to metallic gold, even in solution, which in fact renders Au-azpy suitable for further biological studies.

\subsection{Pyrido[2,1-c][1,2,4]benzotriazin-11-ium chloride, $\mathrm{C}_{11} \mathrm{H}_{8} \mathrm{~N}_{3} \mathrm{Cl} \cdot \mathrm{H}_{2} \mathrm{O}$, pyrium}

The schematic representation of the new cationic species is shown in Scheme 2.

The synthesis was found to be fully reproducible in the four used solvents acetone, acetonitrile, ethanol and methanol, and all gave the same product. Using acetonitrile and methanol the complete conversion took 24 days at ambient conditions, whereas 12 days were required in case of acetone. The ESI-MS spectrum exhibits the highest mass peak at $m / z=181.94$, which corresponds to the cationic species, $\mathrm{C}_{11} \mathrm{H}_{8} \mathrm{~N}_{3}^{+}$. The peaks display the correct isotopomer distribution.

${ }^{1} \mathrm{H}$ NMR spectrum is in agreement with the structure proposed by X-ray diffraction. Seven different peaks (one pair overlapping) are observed. The integration values are in agreement with the molecular formula proposed ( $8 \mathrm{H}$ atoms). The complete peak assignment was performed by ${ }^{1} \mathrm{H}$ COSY determination (spectrum shown in the supplementary data, Fig. S4). The final spectrum is depicted in Fig. 6.

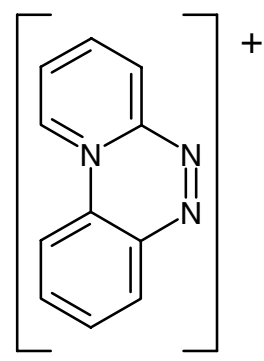

Scheme 2. Schematic representation of the pyrium cation.

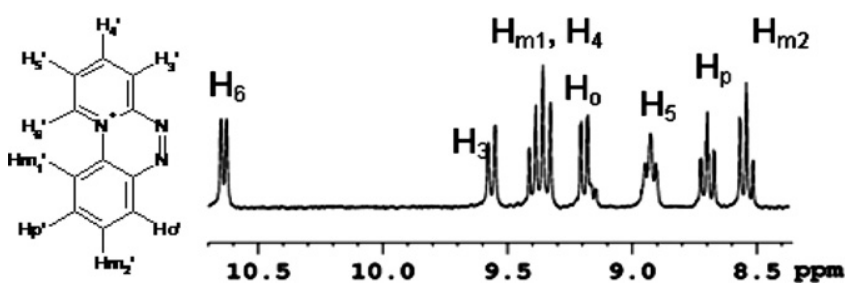

Fig. 6. ${ }^{1} \mathrm{H}$ NMR spectrum of pyrium in deuterated acetone at $21{ }^{\circ} \mathrm{C}$, using TMS as internal standard. Aromatic region. 
Due to asymmetry, different peaks are observed. The presence of $\mathrm{H}_{6}^{\prime}$ at low field is explained by the strong deshielding effect of the positively charge on the pyridine nitrogen.

\subsection{Crystallography}

After several days, light yellow needles, were recovered from the ${ }^{1} \mathrm{H}$ NMR tube and X-ray diffraction studies were performed on an isolated single crystal. The crystal data suffer from serious crystal defects as evidenced with synthetic precession images derived from the CCD images. Further details are listed in the supplementary data. The thermodynamically stable final compound was named as pyrido[2,1-c][1,2,4]benzotriazin-11-ium chloride. The molecular structure is shown in Fig. 7. The crystal data and selected bond lengths of pyrium are summarized in Table S2.

The results from the X-ray diffraction analysis indicate an organic, aromatic cationic structure, in which $\mathrm{Cl}^{-}$ anions function as counter ion. A water molecule is also present in the asymmetric unit (Fig. 7). The organic cation is disordered over a crystallographic mirror (supplementary data, Fig. S1). The water molecules form an infinite, cooperative chain of hydrogen bonds, capped at the sides by $\mathrm{Cl}^{-}$ions (supplementary data, Fig. S2).

The analysis of this charged organic structure in fact suggests the formation of an organometallic gold intermediate, prior to cyclization; however, the time-dependent ${ }^{1} \mathrm{H}$ NMR stability studies do not present any indication of intermediate species. The integration values obtained from the ${ }^{1} \mathrm{H}$ NMR spectrum of $A u$-azpy clearly show the presence of nine protons in agreement with the proposed structure. It is well known that organometallics containing metal-ligand $\sigma$ bonds are characterized by long-wavelength LMCT absorptions [34]; however, these are not observed in the corresponding electronic spectra. The ill-defined nature of other products formed during the synthesis of pyrium has precluded electron accounting and possible elucidation of the reaction stoichiometry and mechanistic proposal. The formation of $\operatorname{Au}(0)$ has not been observed and the
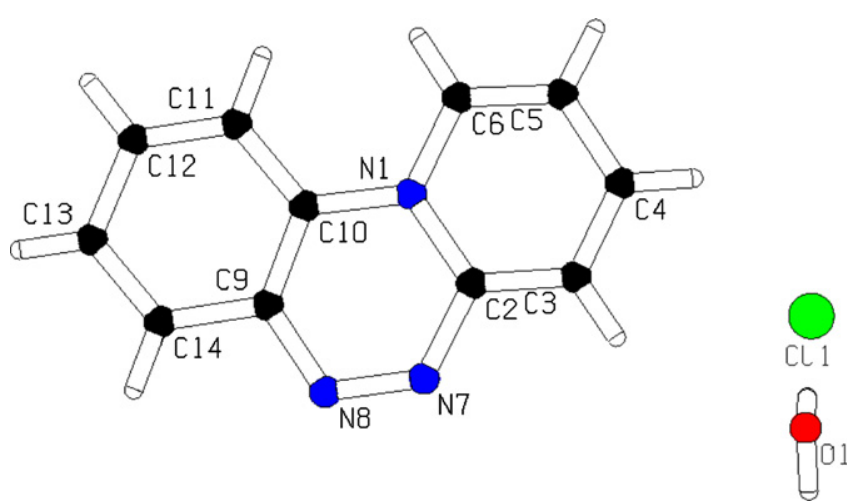

Fig. 7. Molecular structure of the asymmetric unit of pyrium with atomnumbering. present chemical evidence is suggesting the presence of $\mathrm{Au}(\mathrm{III})$ in solutions after complete conversion to pyrium. Although not studied in detail, the role of the solvent must be critical in this transformation. Further research is planned, using substituted ligands, towards understanding a reaction mechanism. This however, is beyond the scope of the present study.

To the best of our knowledge the heterocyclic structure reported here is the first pyrido[2,1-c][1,2,4]benzotriazin11-ium core described in literature. We mention that, under irradiation, azobenzenes could undergo cyclodehydrogenation forming then benzo $[c]$ cinnoline when proton acids [36] or Lewis acids $[37,38]$ are present. In fact a somewhat related compound was reported to Pillai and Purushothaman [39] when photocyclization of azpy was induced. Their final product, 4-pyrido[ $[c]$ cinnoline (Scheme 3, right figure) was barely characterized.

\subsection{Cytotoxic activity studies}

The purity of the compounds described in this report has been estimated by elemental analysis, IR spectroscopy, ${ }^{1} \mathrm{H}$ NMR spectrometry, chromatography and equivalent conductance and after completing the characterization the cytotoxic properties were determined.

The cytotoxicity of $\mathrm{HAuCl}_{4}, a z p y, A u$-azpy, pyrium and with cisplatin as a reference compound, was studied using the following human tumor cell lines, A2780, sensitive and A2780R resistant to cisplatin and murine cell line L1210, sensitive and resistant to cisplatin. The most important data have been summarized in Table 1. In order to asses a possible lack of cross resistance with cisplatin, the cytotoxic activity was determined in cell lines sensitive and resistant to cisplatin. Cisplatin, azpy and $\mathrm{HAuCl}_{4}$ were included as reference compounds and have been evaluated under the same conditions. Cross resistance profiles were evaluated by means of the resistance factor (RF), which is defined as the ratio between $\mathrm{IC}_{50}$ values calculated for cisplatin-resistant cell line and the sensitive parental cell line, respectively $\left(\mathrm{RF}=\mathrm{IC}_{50 \text { resistant }} / \mathrm{IC}_{50 \text { sensitive }}\right)$.

On the basis of these results, all compounds tested in the non-resistant A2780 cell line show a lower cytotoxic effect than cisplatin, but all compounds present $\mathrm{IC}_{50}$ values

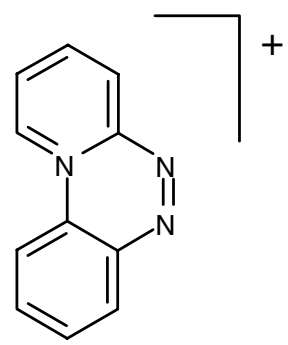

pyrido[2,1-c][1,2,4]benzotriazin-11-ium chloride

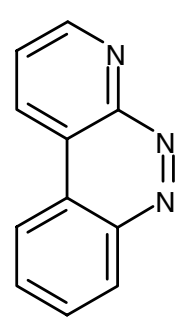

4-pyrido[c]cinnoline

Scheme 3. Schematic representation of pyrium and a related 4-pyrido $[c]$ cinnoline. 
Table 1

In vitro cytotoxicity assay of compounds synthesized incubated during $72 \mathrm{~h}$

\begin{tabular}{|c|c|c|c|c|c|c|}
\hline Cell line & A 2780 & A2780R & $\mathrm{RF}$ & L1210/0 & L1210/2 & $\mathrm{RF}$ \\
\hline \multicolumn{7}{|c|}{$I C_{50}$ mean values $(\mu M) \pm s d$} \\
\hline $\mathrm{HAuCl}_{4}$ & $19.2 \pm 1.8$ & $15.9 \pm 2.1$ & 0.82 & $18.5 \pm 3.1$ & $18.2 \pm 3.5$ & 0.98 \\
\hline azpy & $23.1 \pm 1.3$ & $26.4 \pm 1.6$ & 1.14 & $22.6 \pm 3.6$ & $45.6 \pm 2.9$ & 2.01 \\
\hline$A u-a z p y$ & $10.5 \pm 2.4$ & $12.6 \pm 1.3$ & 1.20 & $56.7 \pm 2.6$ & $62.5 \pm 3.1$ & 1.10 \\
\hline Pyrium & $9.2 \pm 1.2$ & $5.4 \pm 1.7$ & 0.59 & $17.0 \pm 2.1$ & $10.6 \pm 2.5$ & 0.62 \\
\hline Cisplatin & $2.42 \pm 1.3$ & $9.9 \pm 1.8$ & 4.06 & $2.08 \pm 3.6$ & $19.9 \pm 2.3$ & 9.6 \\
\hline
\end{tabular}

within the micromolar range, which is generally considered to be a promising cytotoxic activity. The $\mathrm{Au}$ (III) compounds show significant cytotoxic activity, with $\mathrm{IC}_{50}$ values ranging from 10-62 $\mu \mathrm{M}$. Similar values have been observed in other $\mathrm{Au}(\mathrm{III})$-pyridine containing compounds [19]. The $\mathrm{AuCl}_{4}^{-}$ion is also quite cytotoxic and clearly a minimum degree of cross resistance is observed in both solid tumors and in the leukemia cells. The Au-azpy shows high cytotoxic activity in the human solid tumors, but lower toxicity in leukemia cells. In addition some degree of cross resistance is observed. This evidence probes that $A u$-azpy is able to travel inside the cells. Important cytotoxic effect was also observed by azpy in the tested cell lines.

In particular it should be pointed out that the new cation pyrium has a high cytotoxic activity. In fact pyrium shows a cytotoxic activity within the same range as found for cisplatin in the sensitive line and it is even significantly more cytotoxic than cisplatin in the resistant cell lines, where it is at least 2 times more cytotoxic than cisplatin; this implies that the tricyclic product does overcome cisplatin resistance. For A2780R, studies indicate that the mechanism of resistance to cisplatin is multifactorial involving increased DNA repair, decreased drug uptake and elevated glutathione levels and some evidence underline the charge as an important factor involved in antitumor activity. Anyway more studies with different cell lines and in vitro studies with biologically relevant fluids should be developed. The murine models have been of some value in identifying agents effective in the treatment of human leukaemia and lymphomas. Remarkably $A u$ azpy, $\mathrm{HAuCl}_{4}$ and pyrium retain a high cytotoxicity towards the cisplatin resistant cell line. The cytotoxic activity of the free ligand does not diminished the fact that the presence of $\mathrm{Au}(\mathrm{III})$ increased substantially the cytotoxic properties and even non-cross resistance effect.

\section{Concluding remarks}

The main motivation of the present research originated from the relatively little knowledge of the mechanism of action of gold drugs in particular in field of cancer treatment. The synthesis and characterization of a $\mathrm{Au}(\mathrm{III})$ coordination compound with the bidentate ligand, azpy, were found to be successful, although single crystals suitable for X-ray diffraction of the Au-azpy complex were not obtained. However, its structure can be reasonably pro- posed, and the conclusions reached from spectroscopic techniques indicate that coordination takes place in a near-square-planar geometry through the nitrogen-donating atoms from the pyridine ring and the nitrogen of the azo group in a bidentate mode.

The present work also demonstrates that 2-(phenylazo)pyridine once coordinated is susceptible to remarkable metal-mediated organic reactions. It has been shown that the $-\mathrm{C}_{6} \mathrm{H}_{5}$ moiety of azpy shows cyclization to the pyridine ring, as a result of which a tricyclic positively charged cationic structure is produced, which is described for the first time here.

Both $A u$-azpy and pyrium display an interesting cytotoxic profile against the cell lines tested. Remarkably the $\mathrm{IC}_{50}$ values are in the micromolar range. In particular $p y r-$ ium possesses significantly more potent cytotoxic effects and noticeable non-cross resistance was observed. Even though a hypothesis in the mechanism of action could not yet be formulated based on the present evidence, it is clear that heterocyclic $\mathrm{Au}(\mathrm{III})$ compounds are promising for future studies.

\section{Acknowledgments}

This work was supported in part (A.L.S.) by the Council for the Chemical Sciences of the Netherlands Organization for Scientific Research (CW-NWO) and in part by generous support for this work was provided by CONACYT (National Council of Science and Technology) as a doctoral fellowship to A.G.O. We thank A.W.M. Lefeber for assistance with the NMR techniques, Jos van Brussel for the ICP-gold determination, John A.P.P. van Dijk for the ESI-MS determinations and Jopie A. Erkelens-Duijndam. The A2780 and A2780R cell lines were generously supplied by Prof. Dr. Carmen Navarro Ranninger (Universidad Autónoma de Madrid, Spain).

\section{Appendix A. Supplementary data}

Complete experimental data, experimental details and compound spectral characterization, Infrared table, X-ray diffraction studies and related parameters. This material is available free of charge via the internet at Crystallographic data for the pyrium compound has been deposited with the Cambridge Crystallographic Data center (CCDC 637636). Supplementary data associated with this article 
can be found, in the online version, at doi:10.1016/ j.jinorgbio.2007.05.008.

\section{References}

[1] C.X. Zhang, S.J. Lippard, Curr. Opin. Chem. Biol. 7 (2003) 481-489.

[2] J.M. Hill, R.J. Speer, Anticancer Res. 2 (1982) 173-186.

[3] J. Reedijk, Chem. Commun. (1996) 801-806.

[4] E. Wong, C.M. Giandomenico, Chem. Rev. 99 (1999) 2451-2466.

[5] J. Reedijk, Proc. Nat. Acad. Sci. USA 100 (2003) 3611-3616.

[6] I. Kostova, Recent Patents Anticancer Drug Discovery 1 (2006) 1-22.

[7] P. Köpf-Maier, Eur. J. Clin. Pharmacol. 47 (1994) 1-16.

[8] C.F. Shaw III, Chem. Rev. 99 (1999) 2589-2600.

[9] S.P. Fricker, Gold Bull. 29 (1996) 53-59.

[10] E.R.T. Tiekink, Crit. Rev. Oncol./Hematol. 42 (2002) 225-248.

[11] Z. Huaizhi, N. Yuantao, Gold Bull. 34 (2001) 24-29.

[12] W.F. Kean, F. Forestier, Y. Kassam, W.W. Buchanan, P.J. Rooney, Semin. Arthritis Rheum. 14 (1985) 180-186.

[13] E.R.T. Tiekink, Gold Bull. 36 (2003) 117-124.

[14] N. Campbell, A.W. Henderson, D. Taylor, J. Chem. Soc. (1953) 1281-1285.

[15] R.A. Krause, K. Krause, Inorg. Chem. 19 (1980) 2600-2603.

[16] A.C.G. Hotze, A.H. Velders, F. Ugozolli, M. Biagini-Cingi, A.M. Manotti-Lanfredi, J.G. Haasnoot, J. Reedijk, Inorg. Chem. 39 (2000) 3838-3844.

[17] A.H. Velders, H. Kooijman, A.L. Spek, J.G. Haasnoot, D. de Vos, J. Reedijk, Inorg. Chem. 39 (2000) 2966-2967.

[18] L. Ronconi, L. Giovagnini, C. Marzano, F. Bettio, R. Graziani, Inorg. Chem. 44 (2005) 1867-1881.

[19] P. Calamai, S. Carotti, A. Guerri, T. Mazzei, L. Messori, E. Mini, P. Orioli, G.P. Speroni, Anti-Cancer Drug Des. 13 (1998) 67-80.

[20] S. Carotti, A. Guerri, T. Mazzei, L. Messori, E. Mini, P. Orioli, Inorg. Chim. Acta 281 (1998) 90-94.
[21] L. Ronconi, C. Marzano, P. Zanello, M. Corsini, G. Miolo, C. Macca, A. Trevisan, D. Fregona, J. Med. Chem. 49 (2006) 1648-1657.

[22] M.J. McKeage, L. Maharaj, S.J. Berners-Price, Coord. Chem. Rev. 232 (2002) 127-135.

[23] M.P. Rigobello, L. Messori, G. Marcon, M.A. Cinellu, M. Bragadin, A. Folda, G. Scutari, A. Bindoli, J. Inorg. Biochem. 98 (2004) 1634 1641.

[24] A. Eva, K.C. Robbins, P.R. Andersen, A. Srinivasan, S.R. Tronick, E.P. Reddy, N.W. Ellmore, A.T. Galen, J.A. Lautenberger, T.S. Papas, E.H. Westin, F. Wongstaal, R.C. Gallo, S.A. Aaronson, Nature 295 (1982) 116-119.

[25] A. Eastman, S. Illenye, Cancer Treat. Rep. 68 (1984) 1189-1190.

[26] M.C. Alley, D.A. Scudiero, A. Monks, M.L. Hursey, M.J. Czerwinski, D.L. Fine, B.J. Abbott, J.G. Mayo, R.H. Shoemaker, M.R. Boyd, Cancer Res. 48 (1988) 589-601.

[27] H. Tada, O. Shiho, K. Kuroshima, M. Koyama, K. Tsukamoto, J. Immunol. Methods 93 (1986) 157-165.

[28] T. Mosmann, J. Immunol. Methods 65 (1983) 55-63.

[29] T.F. Slater, B. Sawyer, U. Strauli, Biochim. Biophys. Acta 77 (1963) 383-393.

[30] W.J. Geary, Coord. Chem. Rev. 7 (1971) 81-123.

[31] J. Vicente, M.T. Chicote, D. Bermudez, Inorg. Chim. Acta 63 (1982) $35-39$.

[32] R. Krause, K. Krause, Inorg. Chem. 21 (1982) 1714-1720.

[33] F.H. Fry, G.A. Hamilton, J. Turkevich, Inorg. Chem. 5 (1966) 1943 1946.

[34] A. Vogler, H. Kunkely, Coord. Chem. Rev. 219-221 (2001) 489-507.

[35] R.V. Parish, Gold Bull. 30 (1997) 3-12.

[36] G.E. Lewis, J. Org. Chem. 25 (1960) 2193-2195.

[37] C.P. Joshua, R.V.N. Pillai, Tetrahedron Lett. (1972) 2493-2494.

[38] C.P. Joshua, V.N.R. Pillai, Tetrahedron 30 (1974) 3333-3337.

[39] V.N.R. Pillai, E. Purushothaman, Curr. Sci. 46 (1977) 381-382. 